\title{
Processing of cenosphere/HDPE syntactic foams using an industrial scale polymer injection molding machine
}

\author{
B. R. Bharath Kumar ${ }^{1}$, Mrityunjay Doddamani ${ }^{1}$, Steven E. Zeltmann ${ }^{2}$, Nikhil Gupta ${ }^{2}$, M. R. \\ Ramesh $^{1}$ and Seeram Ramakrishna ${ }^{3}$ \\ ${ }^{1}$ Lightweight Materials Laboratory, Department of Mechanical Engineering, National Institute of \\ Technology Karnataka, Surathkal, India, *Tel.: +91 9448920878, \\ Email: mrdoddamani@nitk.edu.in \\ ${ }^{2}$ Composite Materials and Mechanics Laboratory, Mechanical and Aerospace Engineering \\ Department, Tandon School of Engineering, New York University, Brooklyn, NY 11201 USA, \\ Email: ngupta@nyu.edu \\ ${ }^{3}$ Center for Nanofibers \& Nanotechnology, National University of Singapore, Singapore
}

\begin{abstract}
Rapid production of high quality components is the key to cost reduction industrial applications. The present work is the first attempt of manufacturing syntactic foams, hollow particle filled lightweight composites, using an industrial scale injection molding machine. High density polyethylene (HDPE) is used as the matrix material and fly ash cenospheres are used as the filler. Development of syntactic foams with cenospheres serves dual purpose of beneficial utilization of industrial waste fly ash and reduction in the cost of the component. The pressure and temperature used in injection molding process are optimized to minimize fracture of cenospheres and obtain complete mixing of cenospheres with HDPE. The optimized parameters are used for manufacturing syntactic foams with 20, 40 and $60 \mathrm{wt} . \%$ cenospheres. With increasing cenosphere content, density and strength reduce and modulus increases. Surface modification of constituents results in rise in strength with increasing filler content. A theoretical model based on a differential scheme is used to estimate the properties of cenospheres by conducting parametric studies because of inherent difficulties in direct measurement of cenosphere properties. The potential for using the optimized injection molding process is demonstrated by casting several industrial components.
\end{abstract}

Keywords: Syntactic foam; injection molding; theoretical modeling; high density polyethylene; fly ash cenosphere. 


\section{Introduction}

Polymer matrix composites can reduce the structural weight and result in improved fuel efficiency and performance in transportation applications. Thermoplastic matrix composites have been used for semi-structural and engineering applications. In addition to the ease of fabrication using a wide range of forming processes, thermoplastic polymers are recyclable, which are strong driving forces for their current and future applications. The present study is focused on using high density polyethylene (HDPE) to fabricate hollow particle filled lightweight composite materials, called syntactic foams [1-3], using an industrial scale polymer injection molding (PIM) process. Selecting hollow particles of appropriate characteristics can result in syntactic foams with higher specific strength, lower coefficient of thermal expansion, and radar or sonar transparency than the matrix resin [4]. Many of the applications of syntactic foams are related to marine environment, where buoyancy obtained from lightweight materials is important $[4,5]$.

Commodity plastics such as low and high density polyethylene and polypropylene find widespread applications in consumer goods due to low cost manufacturing in large production runs. HDPE is used in products such as beverage bottles, storage bins, automotive molded parts and casing for consumer electronic items $[6,7]$. These thermoplastic matrix composites combine ease of processing with property advantages such as enhanced toughness and an unlimited shelf life. Dimensional stability, weight consistency, satisfactory visual impression and durability in the end-use application help these composites meet the quality criteria. Enhancement in properties of these materials is highly desirable, especially with fillers that can be integrated with the existing manufacturing methods. Fillers that can improve properties such as stiffness, thermal resistance, and shrinkage are beneficial. Use of fillers can also help in reducing the consumption of polymer in making the part, which can further help protect the environment and make the part cheaper.

Fly ash cenospheres are among the hollow particle fillers used in syntactic foams fabricated with polymer and metal matrices [8]. Cenospheres are lightweight hollow spherical particles extracted from coal combustion by-products and can be used as fillers in syntactic foams. Use of industrial waste materials like cenospheres in a beneficial application can also help in addressing the environmental issues related to their disposal and long term storage [9]. Cenospheres comprise of alumina, silica and other ceramic materials. Defects in the walls limit their performance and require innovative methods for incorporating them in polymers to make 
composites. In the past studies, the most common examples of using cenospheres as fillers can be found with epoxy resin and aluminum matrices $[10,11]$. Fly ash filled polypropylene and phenolic matrix composites have also been studied previously [12-16]. There has been significant interest in studying the wear characteristics of fly ash reinforced composites [17-20]. Incorporation of these low cost ceramic fillers can reduce the wear rate as shown in these studies.

PIM is a widely used manufacturing method for HDPE parts. In this process, the molten polymer is injected into the mold, where it cools and finally the finished plastic part is ejected. PIM method is capable of economically producing precision plastic parts with various shapes and complex geometries at low cost. However, the existing studies have not utilized such mainstream industrial production methods for producing syntactic foams. The present work focuses on two aspects (a) development of HDPE matrix syntactic foams and (b) utilization of a well-established PIM method for fabricating syntactic foam parts. If such rapid manufacturing technique can be developed for syntactic foam parts, the cost of such lightweight eco-friendly components can be lowered. The main challenges in adapting the PIM method for fabrication of syntactic foams are (a) optimizing pressure and temperature to ensure that neither incomplete mold filling nor overpressure is achieved, (b) minimizing the hollow particle fracture and (c) uniform mixing of lightweight particles in the matrix resin within the PIM process.

In the present study, the PIM process is first optimized for process temperature and pressure to minimize the filler breakage. The optimum combination of parameters is then used to manufacture syntactic foams with 20 (HDPE20), 40 (HDPE40) and 60 (HDPE60) wt.\% cenospheres without any surface modification. Neat HDPE matrix samples are also cast under similar conditions for comparative study. Further, samples with functionalized HDPE and silane surface treated cenospheres are cast for comparative study to understand the effect of interfacial strength on tensile properties. Tensile testing is conducted on the manufactured specimens. Modulus results are compared with existing theoretical models to understand the properties of cenosphere particles. Finally, several prototype components of cenosphere/HDPE syntactic foams are molded for comparison with neat HDPE components to understand the potential of saving HDPE resin through use of cenosphere filler. 


\section{Experimental}

\section{$2.1 \quad$ Materials}

HDPE of grade HD50MA180 supplied by Reliance Polymers, Mumbai, India is used as the matrix material. Cenosphere of CIL-150 grade, supplied by Cenosphere India Pvt. Ltd., Kolkata, India, are used as hollow fillers. Cenospheres are used in the as supplied condition, without any surface treatment. Chemical, physical and sieve analysis results provided by the supplier of cenospheres are available in the data set that accompanies this work [21]. Cenospheres primarily comprise of alumina, silica, calcium oxide and iron oxides as observed in this table.

\subsection{Fabrication Process}

Cenospheres and HDPE in as-received condition (untreated) were mechanically premixed in the desired proportions and loaded into the hopper of a horizontal type PIM machine. Interfacial adhesion determines effectiveness of stress transfer between the constituents. Cenospheres in 50 g quantity were mixed into the solution of water/ethanol (20:80 wt. \%) maintained at $80^{\circ} \mathrm{C}$. 3 -Amino propyl tri ethoxy silane by $2 \%$ volume is added into the solution and continuously stirred for 30 minutes at $80^{\circ} \mathrm{C}$. Resultant product was filtered and washed at least three times using a mix of water/ethanol and dried in an oven to extract the coated cenospheres. HDPE $(50 \mathrm{~g})$ is mixed with $5 \mathrm{ml}$ of dibutyl maleate (functionalizer) and $0.15 \mathrm{~g}$ of dicumyl peroxide (initiator for compatibilization between silane coated cenosphere and functionalized HDPE). The blend was mixed in the Brabender (CMEI, MODEL-16 CME SPL, Western Company Keltron) at $165^{\circ} \mathrm{C}$ for 10 minutes [22-24]. These surface treated constituents are also pre-mixed mechanically and loaded in PIM. The schematic representation of the PIM machine is presented in Figure 1a. The specifications of the machine are provided in the published data set [21]. The schematic of signal/material flow in the PIM machine is presented in Figure $1 \mathrm{~b}$ and the tensile test specimen mold is shown in Figure 1c, which produces specimens in accordance with ASTM D 638-10 standard. In the PIM machine a single screw rotates at $30 \mathrm{rpm}$ in the heating zone to uniformly disperse cenospheres in plasticized HDPE. Subsequently, the mixture is injected through the nozzle into the mold of desired cavity shape. Detailed processing conditions for PIM of syntactic foam composites are given in the data set [21]. These parameters were fixed during the present study. 


\subsection{Density measurement}

ASTM D792 - 13 standard was adopted to measure the density of all fabricated specimens. The densities of five specimens were measured and the average values and standard deviations are reported.

\subsection{Tensile testing}

A computer controlled universal test system (Z020 Zwick Roell, USA) with $20 \mathrm{kN}$ load cell was used for tensile testing. A constant crosshead displacement rate is maintained at 50 $\mathrm{mm} / \mathrm{min}$ during the tests. The acquired load and displacement data are used to calculate the stress and strain, respectively. Average modulus and strength values of five specimens for each composite type are reported.

\subsection{Imaging}

Scanning electron microscope (JSM 6380LA, JEOL, Japan) is used for microstructural analysis. All the samples are sputter coated using JFC-1600 auto fine coater (JEOL, Japan). Nikon D7000 camera with Nikkor 35 mm F1.8G lens is used for optical imaging. Tokina AT-X pro $100 \mathrm{~mm}$ F2.8D macro lens is used for imaging fractured features.

\section{Results and Discussion}

\subsection{PIM process optimization and specimen manufacturing}

A pilot study was conducted for optimizing the parameters of PIM process. In this study temperatures of 160 and $180^{\circ} \mathrm{C}$ were used over a wide range of injection pressures in the range $20-50 \mathrm{~kg} / \mathrm{cm}^{2}$ for casting the tensile samples. Since no data is available for optimal parameters for developing cenosphere/HDPE syntactic foams using PIM technique, this parametric optimization is required for manufacturing high quality composites. Composites with 30 and 60 wt.\% cenospheres (labeled as HDPE30 and HDPE60, respectively) were cast in this pilot study.

The composites cast at different pressures are shown in Figure 2. Incomplete filling of mold cavity is obtained in Figure 2 a for applied pressures of 20 and $25 \mathrm{~kg} / \mathrm{cm}^{2}$ for both 160 and $180^{\circ} \mathrm{C}$ temperatures. On the other hand, excessive material squeezing out of the mold is clearly seen in Figure $2 \mathrm{~b}$ for pressures of 45 and $50 \mathrm{~kg} / \mathrm{cm}^{2}$. Figure $2 \mathrm{c}$ shows that high quality specimens are cast at $30-40 \mathrm{~kg} / \mathrm{cm}^{2}$ pressures. High pressure can lead to greater fraction broken cenospheres, while higher temperature leads to lower viscosity of the resin resulting in runoff 
from the mold. Analysis of the density of fabricated specimens can help in measuring the fraction of broken cenospheres.

Density of neat HDPE is measured to be $1.0563 \pm 0.0006 \mathrm{~g} / \mathrm{cm}^{3}$. The measured density values for HDPE30 and HDPE60 syntactic foams manufactured at different combinations of temperatures and pressures are presented in Table 1. It is observed in the table that syntactic foams fabricated at $160^{\circ} \mathrm{C}$ and $30 \mathrm{~kg} / \mathrm{cm}^{2}$ have the lowest densities for both compositions. Higher density values indicate fracture of cenospheres because the samples do not have any porosity in the matrix as observed in representative micrographs presented in Figure 3.

Therefore, temperature and injection pressure of $160^{\circ} \mathrm{C}$ and $30 \mathrm{~kg} / \mathrm{cm}^{2}$, respectively, are selected for casting the syntactic foams in the present study.

\subsection{Density}

Using the optimized parameters of $160^{\circ} \mathrm{C}$ temperature and $30 \mathrm{~kg} / \mathrm{cm}^{2}$ pressure, HDPE20, HDPE40 and HDPE60 specimens are manufactured. Experimentally measured densities, along with theoretical estimates using rule of mixtures, are presented in Table 2. Since no porosity is observed in the matrix resin, the difference between theoretical and experimental density values is attributed to the cenosphere breakage during manufacturing. The estimated filler breakage numbers are presented in Table 2. HDPE60 syntactic foams showing the highest cenosphere breakage for both untreated and treated constituents, have 66.4 vol.\% filler loading. As the filler content increases, the fracture of filler particle also increases due to increased particle to particle interaction and reduction in the mix viscosity. Higher filler breakage is observed for treated constituents as observed in Table 2. Compatibilization of HDPE and cenospheres results in good interfacial bonding. During Cenosphere/HDPE synthesis in PIM, owing to functionalized HDPE, matrix flow around the silane treated particles gets constrained and leads to higher shear forces during mixing in the screw zone (Figure 1a). Further, broken particle fragments have density (about $3.5 \mathrm{~g} / \mathrm{cm}^{3}$ ), which is 3.4 and 2.5 times higher than the density of cenospheres and HDPE matrix, respectively. Although fractured particles do not provide the reduction in density as planned, they still help in replacing more expensive HDPE resin and make the component cheaper. Observations on a freeze fractured surface in Figure $3 \mathrm{~b}$ show a large number of intact particles in HDPE60 syntactic foams manufactured at $160^{\circ} \mathrm{C}, 30 \mathrm{~kg} / \mathrm{cm}^{2}$, apart from debris embedded in the HDPE matrix. The intact particles will be useful in density reduction as well as energy absorption under compression. 
Cenospheres contain defects in their walls. Such defects reduce the strength of cenospheres compared to the value estimated based on their true particle density and wall thickness. Previous studies on hollow $\mathrm{SiC}$ particles with porous walls have shown that such defects can drastically reduce the properties of the particles [25].

\subsection{Tensile behavior}

A representative set of stress-strain graphs for HDPE and syntactic foams are presented in Figure 4. One of the major differences in the trend is that the HDPE specimens show failure strain over $120 \%$, whereas the composite specimens fracture at $8-11 \%$ strain. The failure strain reduces with increasing cenosphere content. The stress-strain graph for the neat resin shows a long perfectly plastic region that ranges from $40-120 \%$ strain. A representative fractured specimen of HDPE is shown in Figure 5. The long necking region in the HDPE specimen corresponds to the large plastic deformation seen in the stress-strain graph. Inset in Figure 5 shows the plastic deformation marks perpendicular to the direction of tensile loading throughout the specimen length. The final failure appears to be fibrous and has a broom-like fracture front. The inset of failure zone in Figure 5 shows such features clearly, where plastic deformation seems to draw the fibers leading to fracture. The failure of syntactic foams appears to be relatively brittle with only a little plastic deformation (see figures in the data set [21]). The failure surfaces presented in for syntactic foams do not show macroscopic deformation as was evident in neat HDPE specimens as seen in these images. Syntactic foams show relatively brittle fracture which can be attributed to stiff cenospheres present in ductile HDPE matrix.

The measured tensile modulus, ultimate tensile strength (UTS), elongation at UTS and failure strength of HDPE and syntactic foams are listed in Table 3. The modulus of syntactic foams increases with cenosphere content. It can also be noted in Table 3 that the UTS decreases with increasing cenosphere content. The matrix is the effective load bearing phase in particulate composites. Decrease in the load bearing section of the composite because of lower matrix content at high cenosphere loading results in reduction in the UTS. The syntactic foam specimens fracture at significantly lower strain compared to the neat HDPE specimens. The average fracture strain for HDPE20, HDPE40 and HDPE60 specimens is measured as 10.38, 9.42 and $7.76 \%$, respectively. The lack of necking and large scale plastic deformation is apparent in the stress strain graphs of syntactic foams. 
The fracture strength of syntactic foams is significantly higher than that of the neat resin. Large scale plastic deformation and progressive reduction in strength result in low fracture strength of HDPE matrix. The combination of ultimate tensile strength and fracture strength should be carefully analyzed. In some applications where large scale plastic deformation after necking is not acceptable or desirable, the use of neat HDPE can be only up to about $10 \%$ strain, where the stress peak appears. This level of strain is comparable for HDPE and syntactic foams. It is also noted that syntactic foams fracture close to their UTS, whereas for neat resin the strength reduces significantly before becoming stable during the necking region.

The failure surface of HDPE resin is observed in Figure 6. Plastic deformation marks that are visible in Figure 5 have deformation features that are smaller than $10 \mu \mathrm{m}$. The failure zone shows extensive fibrous failure. Some of these fibers are of submicron range diameter. The failure surface of HDPE40 is presented in Figure 7. Ductile fracture of the matrix is visible in this image in the form of wide deformation bands which formed due to plastic deformation of resin in the spaces between particles. A dimpled network with the debonded particles dispersed uniformly throughout the matrix is seen in all the fractured syntactic foam samples. Similar features are also observed in HDPE60 in Figure 8a. The plastic deformation of HDPE resin results in formation of fibers that have submicron diameter range as observed in Figure $8 b$. Formation of such fine diameter fibers requires a significant amount of energy because of the creation of very high new surface area. However, comparing the HDPE failure in Figure 6 and syntactic foam failure surface in Figure 8, it is observed that the resin shows much more plastic deformation even at the microscopic level. Further observations on HDPE60 foams in Figure 9a show debris of cenospheres on the fracture surface. Particle matrix interfacial bonding is poor in the present specimens as seen in Figure $9 b$.

Improvement in the interfacial bonding is expected to improve the load transfer from the matrix to the particle and improve the properties of syntactic foams. Previously, similar failure features were observed in tensile failure of epoxy matrix syntactic foams containing glass hollow particles [26]. Use of silane coupling agents has been explored previously in cenosphere/HDPE syntactic foams processed by other methods [22]. Table 4 presents tensile properties obtained for syntactic foams with treated constituents. Functionalization of the HDPE leads to a decrease in the modulus of the matrix. Elongation at UTS and fracture strain decreases with increase in filler content for untreated and treated cases. Elongation at UTS decreases by $71 \%$ for the syntactic 
foams with treated constituents whereas the reduction is $24 \%$ in cases of untreated constituents with respect to the syntactic foam with the lowest filler content. Fracture strain reduces by $25 \%$ in untreated specimens, while a decrease of $52 \%$ was seen with treated constituents. Strength of syntactic foams decreases for untreated, while increases for surface modified constituents, with increasing cenosphere content. These observations can be related to the microstructure of syntactic foams having untreated and treated constituents. Micrographs of representative HDPE60 specimens acquired for untreated and treated constituents are presented in Figure 9. Cenospheres and HDPE are seen to have poor boding in untreated case as depicted by Figure $9 \mathrm{~b}$. Figure 9c shows continuous interface between cenospheres and HDPE resulting in improved interfacial strength in treated constituents. Syntactic foams processed with surface modification show the highest level of strength, especially when the particle content is high. The fracture strength of HDPE60 in untreated decreases by $20 \%$ compared to HDPE20 (Table 4). Fracture strength for HDPE60 rises by only $7 \%$ for treated configuration compared to HDPE20. Though, better adhesion between the constituents is desirable in syntactic foams, surface treatment of constituents must weigh the benefits against increased processing time, costs, and the environmental impacts associated with the chemicals utilized for surface modification. Surface modifications might not always be beneficial and advantageous as it depends on application of the component.

Table 5 presents specific properties of HDPE syntactic foams, which are important in materials selection for weight sensitive applications. A decreasing trend is observed for specific strength with values within the range of $0.014-0.011 \mathrm{MPa} /\left(\mathrm{kg} / \mathrm{m}^{3}\right)$ as the cenosphere content is increased. These values are lower than that for HDPE, which is $0.019 \mathrm{MPa} /\left(\mathrm{kg} / \mathrm{m}^{3}\right)$. Compared to the $E / \rho, E / \rho^{2}$ and $E / \rho^{3}$ values of $0.5\left(\mathrm{MPa} / \mathrm{kg} / \mathrm{m}^{3}\right), 0.47 \times 10^{-3}\left(\mathrm{MPa} /\left(\mathrm{kg} / \mathrm{m}^{3}\right)^{2}\right)$ and $0.45 \times 10^{-6}$ $\left(\mathrm{MPa} /\left(\mathrm{kg} / \mathrm{m}^{3}\right)^{3}\right)$, respectively, all three parameters have higher values for syntactic foams. Higher values of $E / \rho, E / \rho^{2}$ and $E / \rho^{3}$ affirm that the use of syntactic foams can lead to weight savings in molded components. These three parameters appear to be the highest for HDPE40 syntactic foams. Fracture of cenospheres in HDPE60 syntactic foams increases their density and reduces the specific strength and modulus.

\subsection{Theoretical analysis}

A theoretical model developed for syntactic foams and extensively validated with epoxy/glass and vinyl ester/glass microballoon syntactic foams is applied to the 
cenosphere/HDPE syntactic foams [27]. The model involves solving for the elastic properties of a composite containing an infinitely dilute dispersion of hollow particles and extending the results to high particle loadings using a differential scheme. The differential scheme, which contains a correction factor to account for the reduced volume available for hollow particles to occupy as the fraction of particles is increased, is given as

$$
\frac{d E}{E}=f_{E}\left(E_{c}, v_{c}, E_{m}, v_{m}, \eta\right) \frac{d \Phi_{f}}{1-\Phi_{f} / \Phi_{m}}
$$

where $E_{c}$ and $v_{c}$ are the Young's modulus and Poisson's ratio of the ceramic particle wall, $E_{m}$ and $v_{m}$ are the modulus and Poisson's ratio of the matrix material. In addition, $\Phi_{f}$ represents cenosphere volume fraction and $\Phi_{m}$ denotes the maximum packing factor of particles, taken to be 0.637 , which represents the random packing factor of equal size spheres. The modulus of the matrix material is taken from the experimental data and the Poisson's ratio is assumed to be 0.425. To determine the properties of the ceramic walls, the rule of mixtures approach described by [28] is applied using the composition of the fly ash obtained for this study. The presence of minor constituents is ignored, and the modulus and Poisson's ratio of the ceramic are estimated to be $157 \mathrm{GPa}$ and 0.19 , respectively. The parameter $\eta$ is the radius ratio of the hollow particles, defined as the ratio of the inner radius to outer radius. Assuming that the cenosphere wall is uniform and fully dense, the value of $\eta$ can be determined by

$$
\eta=\sqrt[3]{1-\frac{\rho_{T P D}}{\rho_{c}}}
$$

where $\rho_{T P D}$ is the true particle density and $\rho_{c}$ is the density of the ceramic, also obtained by the rule of mixtures for cenosphere considering alumino-silicate composition.

The properties of cenospheres are unknown in the present work as they cannot be meaningfully measured through experiments due to defects in the cenospehre walls. Therefore, parametric studies are conducted using the theoretical model to get an insight into the properties of cenospheres. In Figure 10a, the calculated wall material modulus is kept constant at $157 \mathrm{GPa}$ and the radius ratio is varied to obtain an effective wall thickness for the cenospheres. Close agreement is seen for $\eta=0.995$. Similarly, in Figure $10 \mathrm{~b}$ the wall thickness obtained by density measurements is kept constant corresponding to estimated value of $\eta=0.9$ and the ceramic modulus is varied, with good agreement seen when $E_{c}=7.5 \mathrm{GPa}$. These two pairs of effective 
properties are then used to calculate an effective modulus $\bar{E}$ for the hollow particle using the method developed by [29], given as

$$
\bar{E}=\frac{E_{c}(1-2 v)\left(1-\eta^{3}\right)}{(1-2 v)+\left(\frac{1+v}{2}\right) \eta^{3}}
$$

For both pairs of properties obtained by fitting the theoretical model to the experimental data, the effective particle modulus is calculated to be $1.20 \mathrm{GPa}$ using this method. A similar level of significant reduction in effective properties of hollow particles was observed previously for $\mathrm{SiC}$ particles having porous walls [25, 30]. Selection of higher quality particles is possible with additional steps that involve pressurization of cenospheres to higher pressure and separating out the surviving particles. However, such additional processes add cost and are only justified if the end product can benefit from them. The mathematical model considered perfect bonding between particle and matrix. Some reduction in predicted values is expected if no bonding is assumed. It is also known that change in wall thickness greatly influences the mechanical properties as previously reported [26].

\subsection{Weight saving potential}

Since the low density of syntactic foams is the most promising feature that enables their applications, the trends in mechanical properties are analyzed with respect to density of HDPE matrix with different fillers and are presented in Figure 11 [31-39]. The data are extracted from published literature and are plotted with respect to density. Though a number of articles with HDPE matrix are available many of them did not report the density values. It can be observed from the figure that higher density composites have higher modulus. Only carbon black reinforced HDPE has lower density but comparable modulus as the present composites. Figure 11 shows that with the choice of appropriate constituent materials and concentrations, the tensile strength and modulus can be tailored over a wide range. The tensile modulus and strength are found to be as high as $4.5 \mathrm{GPa}$ and $27 \mathrm{MPa}$, respectively, in HDPE composites. It is desired to have higher mechanical properties for lower densities, where syntactic foams can provide advantage as their specific strength and specific modulus would be comparable to several composites having higher absolute properties. 


\section{Casting of prototype components}

HDPE is widely used in manufacturing consumer products. Many of the existing components can be identified where cenosphere filled HDPE syntactic foams can be beneficial either to provide light weight or to reduce HDPE consumption to make the part cheaper and more eco-friendly. Reduction in failure strain may be a limitation for some applications. In addition, concerns such as mismatch in coefficient of thermal expansion of particle and matrix leading to interfacial separation or material failure can be important considerations. Therefore, the potential applications of such new materials should be carefully selected. Several existing HDPE components are identified and the process parameters optimized in the present work are used to cast these parts in syntactic foams using PIM process. A snapshot of the cast parts is presented in Figure 12.

Table 6 provides details on each of these components and the impact of using syntactic foams for their manufacture. The parts are cast with an aim of reducing the weight of the component by $5 \%$. From Figure 12 it is very clear that, complex shaped, thin sectioned, intricate parts can be manufactured in large volume leading to lower costs. Further, the product is more eco-friendly due to use of fly ash. It is also noted that apart from mixing cenospheres in the initial feed and adjusting molding pressure and temperature, the overall machine settings and parameters have been maintained constant so that the industrial adaptation of lighter components can be easily adopted. Based on the estimate of using HDPE in the selected 9 components, cenosphere usage can save around 2.9 million tons of HDPE globally per year.

\section{Conclusions}

A comprehensive study is conducted to optimize the processing parameters for the polymer injection molding process (PIM) to enable casting of cenosphere/HDPE components. Use of cenospheres can make products lighter and reduce consumption of HDPE. In addition, fly ash is an industrial waste and use of cenospheres in consumer products can reduce the burden on landfills. An industrial scale PIM machine is used to develop the cenosphere/HDPE syntactic foam specimens, which are characterized for tensile properties.

- The most favorable processing parameters for manufacturing syntactic foam with the selected cenospheres and HDPE grade are $160^{\circ} \mathrm{C}$ temperature and $30 \mathrm{~kg} / \mathrm{cm}^{2}$ pressure. 
- Measured density of syntactic foams is higher than their theoretical values suggesting failure of some cenospheres during fabrication. HDPE20 and HDPE40 syntactic foams have lower density than the neat HDPE.

- Syntactic foam specimens fracture at significantly lower strain compared to the neat HDPE specimens but the fracture strength of syntactic foams is significantly higher than that of the neat resin. The modulus of syntactic foams increases with cenosphere content.

- It is also noted that the syntactic foams fracture close to their ultimate strength, whereas for neat resin the strength reduces significantly after reaching a peak and the fracture strength is less than $20 \%$ compared to the peak strength.

- The surface treatment of cenospheres and functionalization of HDPE results in better interfacial adhesion.

- Strength increases with cenosphere content in treated configuration and decreases otherwise. Complex shaped, intricate parts of cenosphere/HDPE syntactic foams can be manufactured in large volume leading to lower costs by using industrial scale injection molding machine.

- From environmental perspective untreated constituents as the better proposition.

\section{Acknowledgments}

Authors acknowledge Dr. Keshav Prabhu, Mr. Puneeth and Mr. Praveen of Konkan Speciality Polyproducts Pvt. Ltd., Mangalore, Karnataka, India for providing the Injection Molding facility for casting the samples and useful discussions. Author Nikhil Gupta acknowledges the Office of Naval Research grant N00014-10-1-0988. The views expressed in this article are those of authors, not of funding agencies. The authors thank the ME Department at NIT-K and MAE Department at NYU for providing facilities and support.

\section{Reference}

1. Shutov, F., Syntactic polymer foams, in Chromatography/Foams/Copolymers. 1986. p. 63-123.

2. Bunn, P. and J.T. Mottram, Manufacture and compression properties of syntactic foams. Composites, 1993. 24(7): p. 565-571. 
3. Gupta, N., E. Woldesenbet, and P. Mensah, Compression properties of syntactic foams: effect of cenosphere radius ratio and specimen aspect ratio. Composites Part A: Applied Science and Manufacturing, 2004. 35(1): p. 103-111.

4. Gupta, N., S. Zeltmann, V. Shunmugasamy, and D. Pinisetty, Applications of Polymer Matrix Syntactic Foams. JOM, 2013: p. 1-10.

5. Gupta, N., D. Pinisetty, and V.C. Shunmugasamy, Reinforced Polymer Matrix Syntactic Foams : Effect of Nano and Micro-Scale Reinforcement. 2013, Cham: Springer International Publishing.

6. Hu, Y., T. Liu, J.L. Ding, and W.H. Zhong, Behavior of high density polyethylene and its nanocomposites under static and dynamic compression loadings. Polymer Composites, 2013. 34(3): p. 417-425.

7. Yang, S., J. Taha-Tijerina, V. Serrato-Diaz, K. Hernandez, and K. Lozano, Dynamic mechanical and thermal analysis of aligned vapor grown carbon nanofiber reinforced polyethylene. Composites Part B: Engineering, 2007. 38(2): p. 228-235.

8. Gupta, N. and P.K. Rohatgi, Metal Matrix Syntactic Foams: Processing, Microstructure, Properties and Applications. 2014: DEStech Publications, Lancaster, PA.

9. Labella, M., S.E. Zeltmann, V.C. Shunmugasamy, N. Gupta, and P.K. Rohatgi, Mechanical and thermal properties of fly ash/vinyl ester syntactic foams. Fuel, 2014. 121: p. 240-249.

10. Daoud, A., Effect of fly ash addition on the structure and compressive properties of 4032-fly ash particle composite foams. Journal of Alloys and Compounds, 2009. 487(12): p. 618-625.

11. Satheesh Raja, R., K. Manisekar, and V. Manikandan, Study on mechanical properties of fly ash impregnated glass fiber reinforced polymer composites using mixture design analysis. Materials \& Design, 2014. 55: p. 499-508.

12. Nath, D.D., S. Bandyopadhyay, J. Rider, A. Yu, D. Blackburn, and C. White, Study of dynamic mechanical properties and morphological behaviours of fly ash reinforced polypropylene composites. Macromolecular Research, 2011. 19(4): p. 338-344.

13. Bandyopadhyay, S., A. Zaeni, D. Nath, A. Yu, Q. Zeng, D. Blackburn, and C. White, Advanced utilization of as received and near whitened fly ash in polypropylene polymer 
to improve mechanical, notched impact and whiteness colour properties. International Journal of Plastics Technology, 2010. 14(1): p. 51-56.

14. Das, A. and B.K. Satapathy, Structural, thermal, mechanical and dynamic mechanical properties of cenosphere filled polypropylene composites. Materials \& Design, 2011. 32(3): p. 1477-1484.

15. Igarza, E., S.G. Pardo, M.J. Abad, J. Cano, M.J. Galante, V. Pettarin, and C. Bernal, Structure-fracture properties relationship for Polypropylene reinforced with fly ash with and without maleic anhydride functionalized isotactic Polypropylene as coupling agent. Materials \& Design, 2014. 55: p. 85-92.

16. Dadkar, N., B.S. Tomar, and B.K. Satapathy, Evaluation of flyash-filled and aramid fibre reinforced hybrid polymer matrix composites $(P M C)$ for friction braking applications. Materials \& Design, 2009. 30(10): p. 4369-4376.

17. Kumar, P.R.S., S. Kumaran, T.S. Rao, and S. Natarajan, High temperature sliding wear behavior of press-extruded AA6061/fly ash composite. Materials Science and Engineering: A, 2010. 527(6): p. 1501-1509.

18. Kumar, V., R.D. Gupta, and N.K. Batra, Comparison of Mechanical Properties and Effect of Sliding Velocity on Wear Properties of Al 6061, Mg 4\%, Fly Ash and Al 6061, Mg 4\%, Graphite 4\%, Fly Ash Hybrid Metal Matrix Composite. Procedia Materials Science, 2014. 6: p. 1365-1375.

19. Ramesh, C.S., S.K. Seshadri, and K.J.L. Iyer, Wear resistance of nickel-fly ash composite coatings. Wear, 1991. 145(1): p. 189-195.

20. Sudarshan and M.K. Surappa, Dry sliding wear of fly ash particle reinforced A356 Al composites. Wear, 2008. 265(3-4): p. 349-360.

21. Bharath Kumar, B.R., M. Doddamani, S.E. Zeltmann, N. Gupta, M.R. Ramesh, and S. Ramakrishna, Data characterizing tensile behavior of censophere/HDPE syntactic foam. Data in Brief, 2015. Submitted.

22. Deepthi, M.V., M. Sharma, R.R.N. Sailaja, P. Anantha, P. Sampathkumaran, and S. Seetharamu, Mechanical and thermal characteristics of high density polyethylene-fly ash Cenospheres composites. Materials \& Design, 2010. 31(4): p. 2051-2060.

23. Divya, V.C., M. Ameen Khan, B. Nageshwar Rao, and R.R.N. Sailaja, High density polyethylene/cenosphere composites reinforced with multi-walled carbon nanotubes: 
Mechanical, thermal and fire retardancy studies. Materials \& Design, 2015. 65: p. 377386.

24. Deepthi, M.V., R.R.N. Sailaja, P. Sampathkumaran, S. Seetharamu, and S. Vynatheya, High density polyethylene and silane treated silicon nitride nanocomposites using highdensity polyethylene functionalized with maleate ester: Mechanical, tribological and thermal properties. Materials \& Design, 2014. 56: p. 685-695.

25. Shunmugasamy, V., S. Zeltmann, N. Gupta, and O. Strbik, III, Compressive Characterization of Single Porous SiC Hollow Particles. JOM, 2014. 66(6): p. 892-897.

26. Gupta, N. and R. Nagorny, Tensile properties of glass microballoon-epoxy resin syntactic foams. Journal of Applied Polymer Science, 2006. 102(2): p. 1254-1261.

27. Aureli, M., M. Porfiri, and N. Gupta, Effect of polydispersivity and porosity on the elastic properties of hollow particle filled composites. Mechanics of Materials, 2010. 42(7): p. 726-739.

28. Matsunaga, T., J.K. Kim, S. Hardcastle, and P.K. Rohatgi, Crystallinity and selected properties of fly ash particles. Materials Science and Engineering: A, 2002. 325(1-2): p. 333-343.

29. Li, G., Y. Zhao, and S.-S. Pang, Analytical modeling of particle size and cluster effects on particulate-filled composite. Materials Science and Engineering A, 1999. 271(1-2): p. 43-52.

30. Labella, M., V.C. Shunmugasamy, O.M. Strbik, and N. Gupta, Compressive and thermal characterization of syntactic foams containing hollow silicon carbide particles with porous shell. Journal of Applied Polymer Science, 2014. 131(17): p. n/a-n/a.

31. Yuan, Q., S.A. Bateman, and D. Wu, Mechanical and Conductive Properties of Carbon Black-filled High-density Polyethylene, Low-density Polyethylene, and Linear Lowdensity Polyethylene. Journal of Thermoplastic Composite Materials, 2009.

32. Adhikary, K.B., C.B. Park, M.R. Islam, and G.M. Rizvi, Effects of Lubricant Content on Extrusion Processing and Mechanical Properties of Wood Flour-High-density Polyethylene Composites. Journal of Thermoplastic Composite Materials, 2011. 24(2): p. 155-171.

33. Khalaf, M.N., Mechanical properties of filled high density polyethylene. Journal of Saudi Chemical Society, 2015. 19(1): p. 88-91. 
34. Ou, R., Y. Xie, M.P. Wolcott, S. Sui, and Q. Wang, Morphology, mechanical properties, and dimensional stability of wood particle/high density polyethylene composites: Effect of removal of wood cell wall composition. Materials \& Design, 2014. 58: p. 339-345.

35. Liu, H., Q. Wu, G. Han, F. Yao, Y. Kojima, and S. Suzuki, Compatibilizing and toughening bamboo flour-filled HDPE composites: Mechanical properties and morphologies. Composites Part A: Applied Science and Manufacturing, 2008. 39(12): p. 1891-1900.

36. Li, Y., Y. Zhang, and Y. Zhang, Morphology and mechanical properties of HDPE/SRP/elastomer composites: effect of elastomer polarity. Polymer Testing, 2004. 23(1): p. 83-90.

37. Ayrilmis, N., Combined effects of boron and compatibilizer on dimensional stability and mechanical properties of wood/HDPE composites. Composites Part B: Engineering, 2013. 44(1): p. 745-749.

38. Homaeigohar, S.S., A.Y. Sadi, J. Javadpour, and A. Khavandi, The effect of reinforcement volume fraction and particle size on the mechanical properties of $\beta$ tricalcium phosphate-high density polyethylene composites. Journal of the European Ceramic Society, 2006. 26(3): p. 273-278.

39. Sim, C.P., P. Cheang, M.H. Liang, and K.A. Khor, Injection moulding of hydroxyapatite composites. Journal of Materials Processing Technology, 1997. 69(1-3): p. 75-78. 
Table 1. Density values of HDPE30 and HDPE60 cast for the pilot study for optimization of process parameters.

\begin{tabular}{cccc}
\hline $\begin{array}{c}\text { Syntactic foam } \\
\text { type }\end{array}$ & $\begin{array}{c}\text { Injection pressure } \\
\left(\mathbf{k g} / \mathbf{c m}^{\mathbf{2}}\right)\end{array}$ & $\begin{array}{c}\text { Density at } \mathbf{1 6 0} \\
\left(\mathbf{g} / \mathbf{c m}^{\mathbf{3}}\right)\end{array}$ & $\begin{array}{c}\text { Density } \mathbf{~ a t ~} \mathbf{~ 1 8 0} \\
\left(\mathbf{g} / \mathbf{c m}^{\mathbf{3}}\right)\end{array}$ \\
\hline & 30 & $1.0122 \pm 0.002$ & $1.0261 \pm 0.003$ \\
HDPE30 & 35 & $1.0356 \pm 0.0021$ & $1.0483 \pm 0.0035$ \\
& 40 & $1.0461 \pm 0.0029$ & $1.0551 \pm 0.0039$ \\
\hline & 30 & $1.0219 \pm 0.0071$ & $1.0774 \pm 0.0095$ \\
HDPE60 & 35 & $1.0701 \pm 0.0092$ & $1.1081 \pm 0.014$ \\
& 40 & $1.0802 \pm 0.011$ & $1.1271 \pm 0.029$ \\
\hline
\end{tabular}

Table 2. Theoretical and experimental density values of syntactic foams and cenosphere breakage during fabrication.

\begin{tabular}{|c|c|c|c|c|c|}
\hline \multirow{3}{*}{$\begin{array}{c}\text { Syntactic } \\
\text { foam } \\
\text { type }\end{array}$} & \multirow{3}{*}{$\Phi_{f}$} & \multirow{2}{*}{\multicolumn{2}{|c|}{ Density $\left(\mathrm{g} / \mathrm{cm}^{3}\right)$}} & \multicolumn{2}{|c|}{ Cenosphere failure during fabrication (\%) } \\
\hline & & & & \multirow{2}{*}{$\begin{array}{c}\text { Untreated } \\
\text { constituents }\end{array}$} & \multirow{2}{*}{$\begin{array}{c}\text { Treated } \\
\text { constituents }\end{array}$} \\
\hline & & Measured & Theoretical & & \\
\hline HDPE20 & 0.229 & $1.0159 \pm 0.0016$ & 0.9976 & 1.83 & 8.56 \\
\hline HDPE40 & 0.442 & $1.0078 \pm 0.0036$ & 0.9430 & 6.87 & 17.82 \\
\hline HDPE60 & 0.664 & $1.0219 \pm 0.0071$ & 0.8923 & 14.5 & 24.85 \\
\hline
\end{tabular}

${ }^{*} \Phi_{f}=$ Cenospheres by volume $\%$. 
Table 3. Average modulus, elongation, strength and fracture behavior of syntactic foams with untreated constituents.

\begin{tabular}{cccccc}
\hline Materials & $\begin{array}{c}\text { Modulus } \\
(\mathbf{M P a})\end{array}$ & UTS (MPa) & $\begin{array}{c}\text { Elongation at } \\
\text { UTS }(\boldsymbol{\%})\end{array}$ & $\begin{array}{c}\text { Fracture } \\
\text { strain }(\boldsymbol{\%})\end{array}$ & $\begin{array}{c}\text { Fracture } \\
\text { strength (MPa) }\end{array}$ \\
\hline HDPE & $529 \pm 19$ & $19.9 \pm 0.26$ & $10.2 \pm 0.13$ & $140.85 \pm 6.86$ & $3.88 \pm 0.19$ \\
HDPE20 & $574 \pm 25$ & $14.1 \pm 0.10$ & $7.4 \pm 0.16$ & $10.38 \pm 0.44$ & $12.95 \pm 0.38$ \\
HDPE40 & $723 \pm 27$ & $12.1 \pm 0.44$ & $6.4 \pm 0.34$ & $9.42 \pm 0.72$ & $11.18 \pm 0.33$ \\
HDPE60 & $661 \pm 65$ & $11 \pm 0.55$ & $5.6 \pm 0.41$ & $7.76 \pm 0.37$ & $10.30 \pm 0.55$ \\
\hline
\end{tabular}

Table 4. Average modulus, elongation, strength and fracture behavior of syntactic foams with treated constituents.

\begin{tabular}{cccccc}
\hline Materials & $\begin{array}{c}\text { Modulus } \\
(\mathbf{M P a})\end{array}$ & UTS (MPa) & $\begin{array}{c}\text { Elongation at } \\
\text { UTS }(\%)\end{array}$ & $\begin{array}{c}\text { Fracture } \\
\text { strain }(\%)\end{array}$ & $\begin{array}{c}\text { Fracture } \\
\text { strength }(\mathbf{M P a})\end{array}$ \\
\hline HDPE & $228 \pm 9$ & $45.8 \pm 1.12$ & $10.2 \pm 0.13$ & $51.91 \pm 2.21$ & $13.73 \pm 0.24$ \\
HDPE20 & $268 \pm 10$ & $14.3 \pm 0.55$ & $10.8 \pm 0.11$ & $11.02 \pm 0.21$ & $13.51 \pm 0.31$ \\
HDPE40 & $351 \pm 14$ & $14.8 \pm 0.67$ & $7.6 \pm 0.28$ & $7.97 \pm 0.33$ & $14.21 \pm 0.56$ \\
HDPE60 & $375 \pm 20$ & $15.3 \pm 0.79$ & $3.1 \pm 0.32$ & $5.34 \pm 0.43$ & $14.47 \pm 0.71$ \\
\hline
\end{tabular}


Table 5. Specific tensile properties of syntactic foams.

\begin{tabular}{ccccc}
\hline Materials & $\begin{array}{c}\text { Specific UTS } \\
\left(\mathbf{M P a} / \mathbf{k g} / \mathbf{m}^{\mathbf{3}}\right) \times \mathbf{1 0}^{-\mathbf{3}}\end{array}$ & $\begin{array}{c}\boldsymbol{E} / \boldsymbol{\rho} \\
\left(\mathbf{M P a} / \mathbf{k g} / \mathbf{m}^{\mathbf{3}}\right)\end{array}$ & $\begin{array}{c}\boldsymbol{E} / \boldsymbol{\rho}^{2} \\
\left(\mathbf{M P a} /\left(\mathbf{k g} / \mathbf{m}^{\mathbf{3}}\right)^{\mathbf{2}}\right) \times \mathbf{1 0}^{-3}\end{array}$ & $\begin{array}{c}\boldsymbol{E} / \boldsymbol{\rho}^{\mathbf{3}} \\
\left(\mathbf{M P a} /\left(\mathbf{k g} / \mathbf{m}^{\mathbf{3}}\right)^{\mathbf{3}}\right) \times \mathbf{1 0}^{\mathbf{6}}\end{array}$ \\
\hline HDPE & 18.84 & 0.501 & 0.474 & 0.449 \\
\hline HDPE20 & 13.88 & 0.565 & 0.556 & 0.547 \\
HDPE40 & 12.01 & 0.717 & 0.712 & 0.706 \\
HDPE60 & 10.76 & 0.647 & 0.633 & 0.619 \\
\hline
\end{tabular}

Table 6. Details of cast syntactic foam components.

\begin{tabular}{|c|c|c|c|c|c|c|c|}
\hline No. & $\begin{array}{l}\text { Component } \\
\text { Name }\end{array}$ & $\begin{array}{c}\text { Wt. of } \\
\text { HDPE } \\
\text { component } \\
\text { (g) }\end{array}$ & $\begin{array}{c}\text { Wt. of } \\
\text { Composite } \\
\text { Component } \\
\text { (g) }\end{array}$ & $\begin{array}{c}\text { Wt. } \\
\text { saving } \\
(\%)\end{array}$ & Features & $\begin{array}{c}\text { Component } \\
\text { functionality }\end{array}$ & $\begin{array}{c}\text { *Annual } \\
\text { total } \\
\text { HDPE } \\
\text { Saving }\end{array}$ \\
\hline 01 & Bearing cover & 11.3 & 10.7 & 5 & $\begin{array}{l}\text { Stepped thin } \\
\text { section }\end{array}$ & $\begin{array}{l}\text { Compliant for being } \\
\text { press fit, sealing, wear } \\
\text { resistance }\end{array}$ & \multirow{9}{*}{$\begin{array}{c}5 \%, \\
2.9 \\
\text { Million } \\
\text { tons }\end{array}$} \\
\hline 02 & $\begin{array}{l}\text { Automobile } \\
\text { component } \\
\text { used in } \\
\text { liquefied } \\
\text { petroleum gas } \\
\text { driven cars }\end{array}$ & 16.8 & 15.9 & 5.5 & $\begin{array}{l}\text { Thin slender } \\
\text { section, } \\
\text { localized steps, } \\
\text { Multiple } \\
\text { features in } \\
\text { different } \\
\text { planes }\end{array}$ & $\begin{array}{l}\text { Sustain compressive } \\
\text { forces, chemically } \\
\text { inert, dimensionally } \\
\text { stable, low coefficient } \\
\text { of thermal expansion, } \\
\text { fire retardant }\end{array}$ & \\
\hline 03 & $\begin{array}{l}\text { Gear for } \\
\text { small motors }\end{array}$ & 33.5 & 31.9 & 4.9 & $\begin{array}{l}\text { Thick section, } \\
\text { sharp edges, }\end{array}$ & $\begin{array}{l}\text { Torsional strength, } \\
\text { high stiffness, wear } \\
\text { resistance, vibration } \\
\text { damping, dimensional } \\
\text { stability at elevated } \\
\text { temperature }\end{array}$ & \\
\hline 04 & $\begin{array}{l}\text { Electrical } \\
\text { connector }\end{array}$ & 25.95 & 24.6 & 5.3 & $\begin{array}{l}\text { Thin section, } \\
\text { thread pockets }\end{array}$ & $\begin{array}{l}\text { Fire retardant, } \\
\text { compliant, long term } \\
\text { durability }\end{array}$ & \\
\hline 05 & $\begin{array}{l}\text { Water filter } \\
\text { cap }\end{array}$ & 13.4 & 12.7 & 5.2 & $\begin{array}{l}\text { Thin section, } \\
\text { screw threads }\end{array}$ & $\begin{array}{l}\text { Close dimensional } \\
\text { tolerances, sealing }\end{array}$ & \\
\hline 06 & $\begin{array}{l}\text { End cap for } \\
\text { closure }\end{array}$ & 28.5 & 27.1 & 5 & Thick section & $\begin{array}{l}\text { Dimensional stability, } \\
\text { compressive and } \\
\text { torsional strength }\end{array}$ & \\
\hline 07 & $\begin{array}{l}\text { Square base } \\
\text { attachment } \\
\text { for pipes }\end{array}$ & 10.7 & 10.2 & 5.3 & $\begin{array}{l}\text { Thin section, } \\
\text { multiple } \\
\text { features in } \\
\text { different } \\
\text { planes }\end{array}$ & $\begin{array}{l}\text { Dimensional stability, } \\
\text { compressive strength, } \\
\text { provide good damping }\end{array}$ & \\
\hline 08 & Jerry can cap & 28.7 & 27.3 & 5.1 & $\begin{array}{l}\text { Thick section, } \\
\text { threads }\end{array}$ & $\begin{array}{l}\text { Compressive strength, } \\
\text { wear resistance, } \\
\text { chemical resistance }\end{array}$ & \\
\hline 09 & $\begin{array}{l}\text { Oil container } \\
\text { packing cap }\end{array}$ & 5.6 & 5.3 & 5 & $\begin{array}{l}\text { Thin section } \\
\text { with step }\end{array}$ & $\begin{array}{l}\text { Compressive strength, } \\
\text { chemical resistance, } \\
\text { fire retardant }\end{array}$ & \\
\hline
\end{tabular}

*Report on Global HDPE demand to grow 4.2\% annually through 2022, March 9, 2015 by Canadian plastics, Toronto, Canada. http://www.canplastics.com/materials/global-hdpe-demand-to-grow-4-2-annually-through-2022report/1003434693 


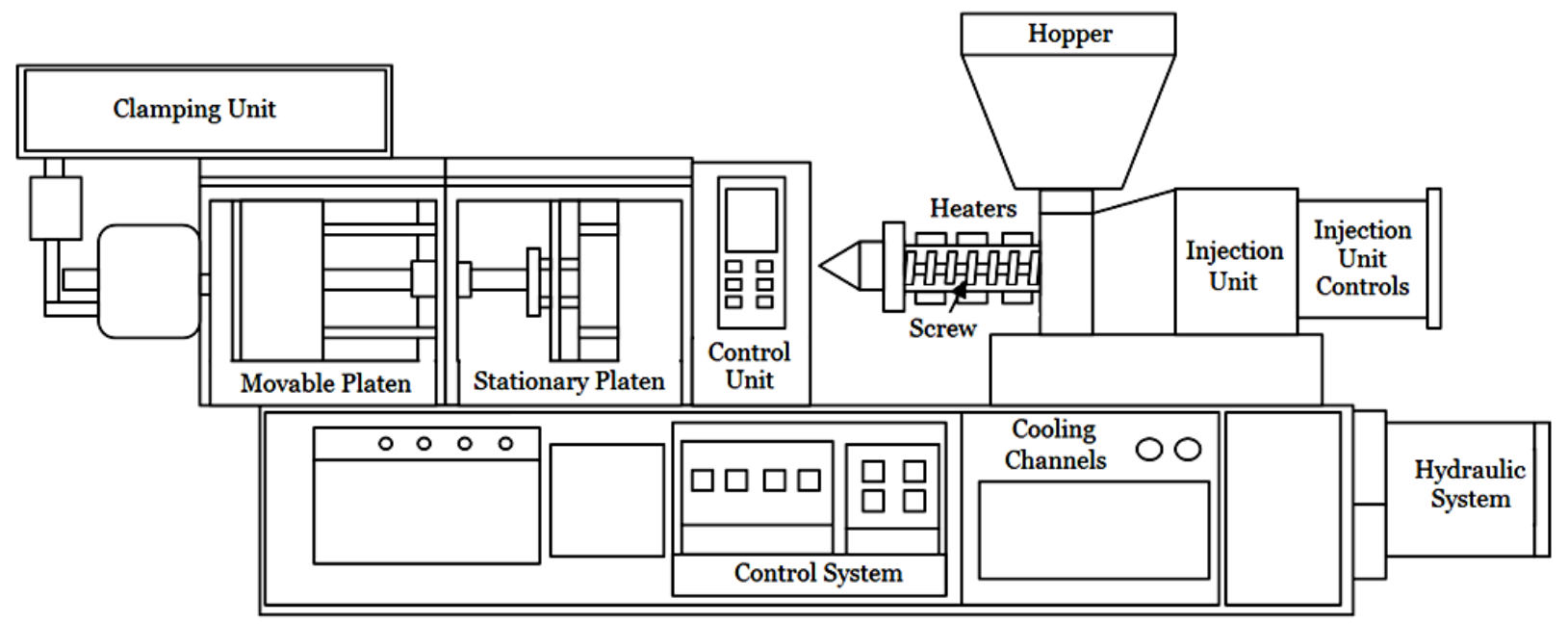

(a)

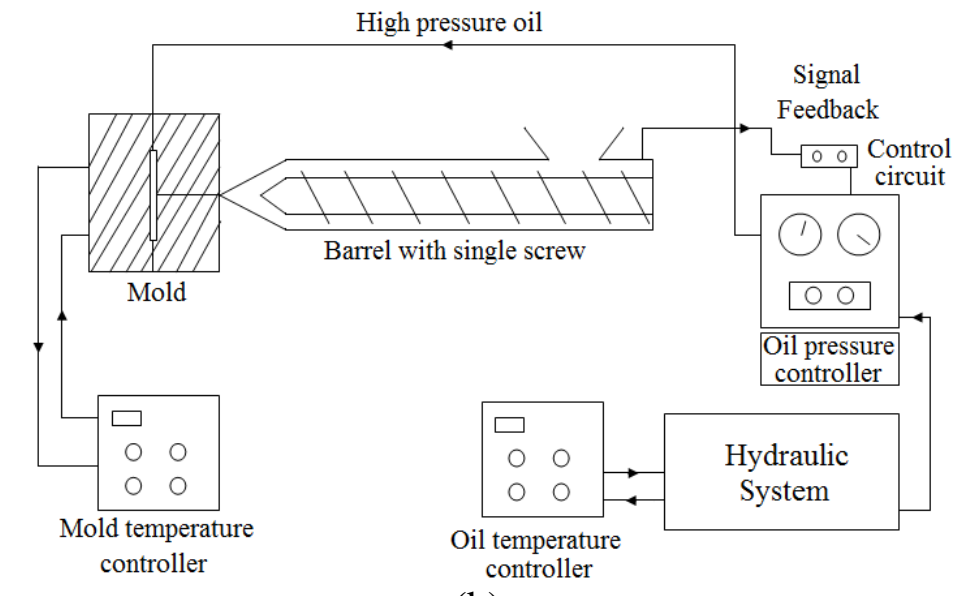

(b)

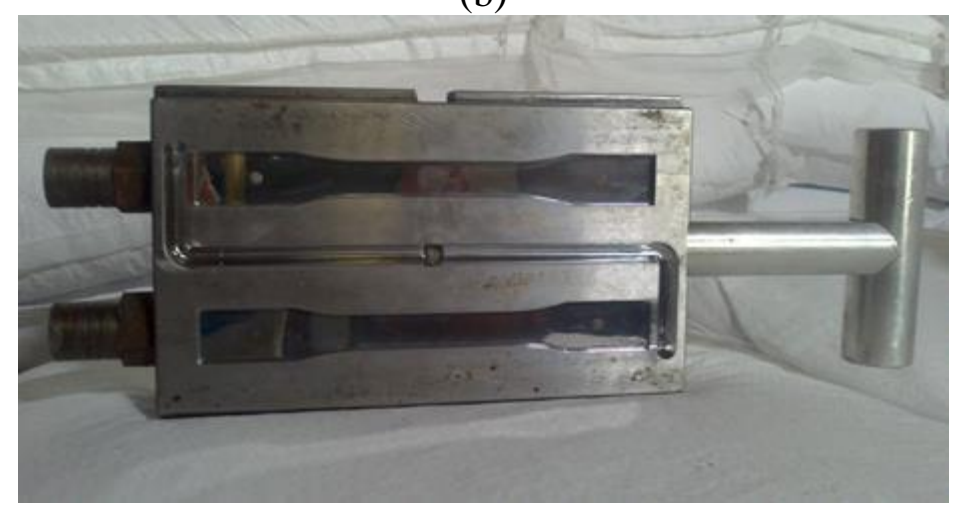

(c)

Figure 1. (a) Schematic of the polymer injection molding machine used for manufacturing syntactic foam specimens. (b) Schematic of signal/material flow in PIM machine. (c) Mold for manufacturing tensile test specimens. 


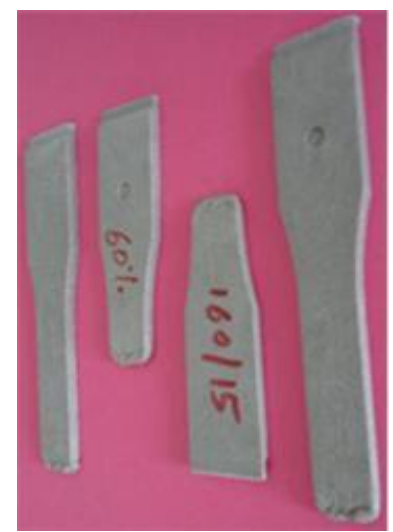

(a)

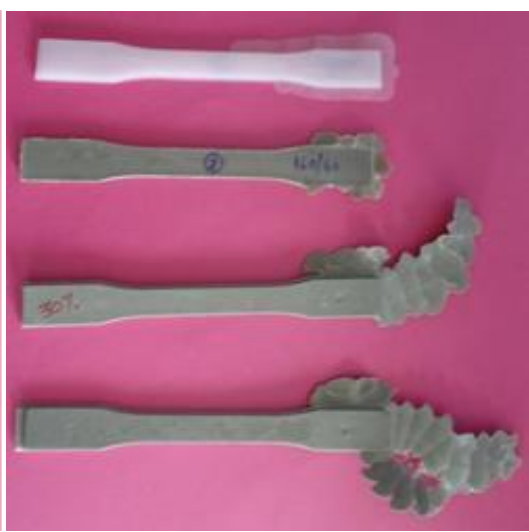

(b)

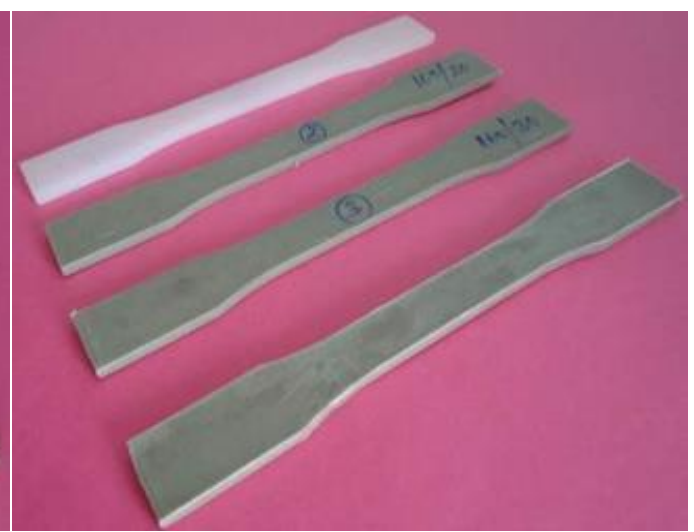

(c)

Figure 2. Syntactic foam samples molded at pressures (a) below $30 \mathrm{~kg} / \mathrm{cm}^{2}$ and (b) above $40 \mathrm{~kg} / \mathrm{cm}^{2}$. (c) The specimens molded at 30,35 and $40 \mathrm{~kg} / \mathrm{cm}^{2}$ pressures showed good quality. The figure includes a neat HDPE specimen with three HDPE60 specimens molded at different pressures.

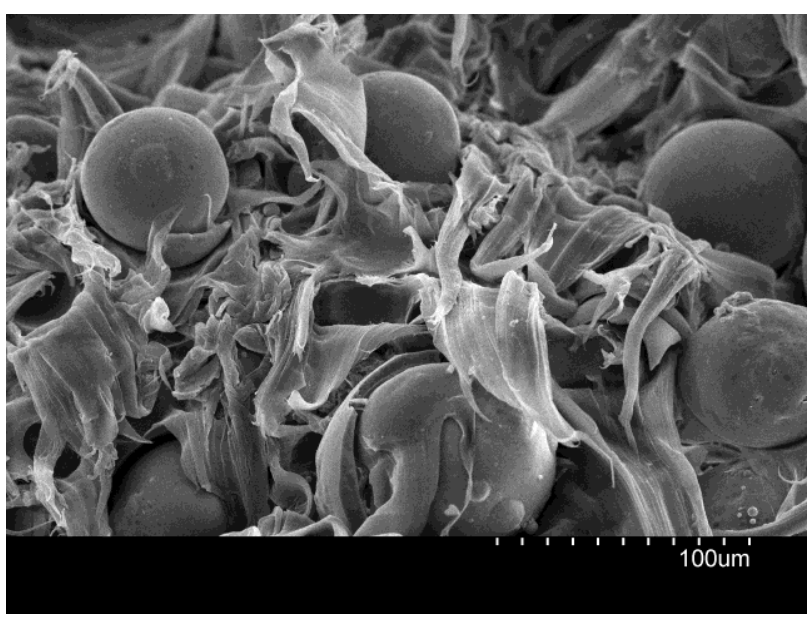

(a)

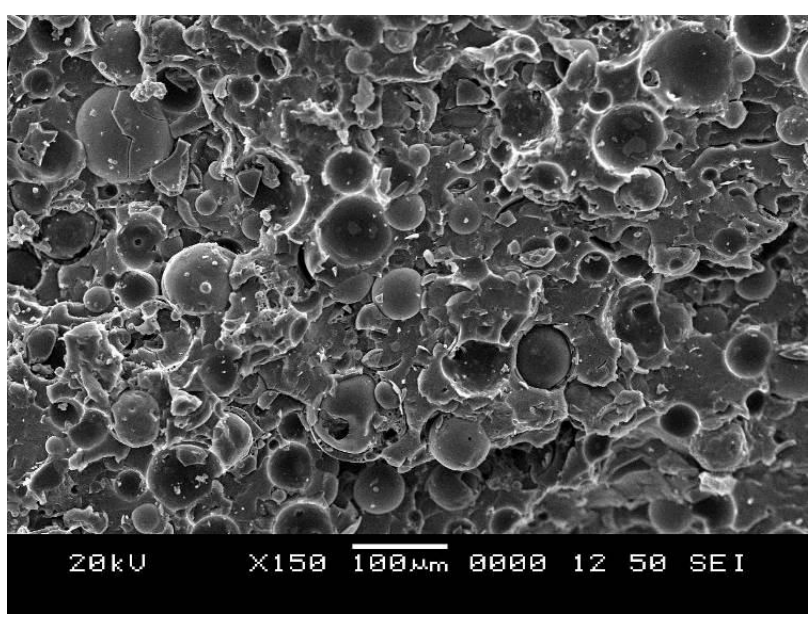

(b)

Figure 3. Micrographs of syntactic foam specimens containing (a) 30 and (b) $60 \mathrm{wt} . \%$ cenospheres manufactured at $160^{\circ} \mathrm{C}, 30 \mathrm{~kg} / \mathrm{cm}^{2}$. 


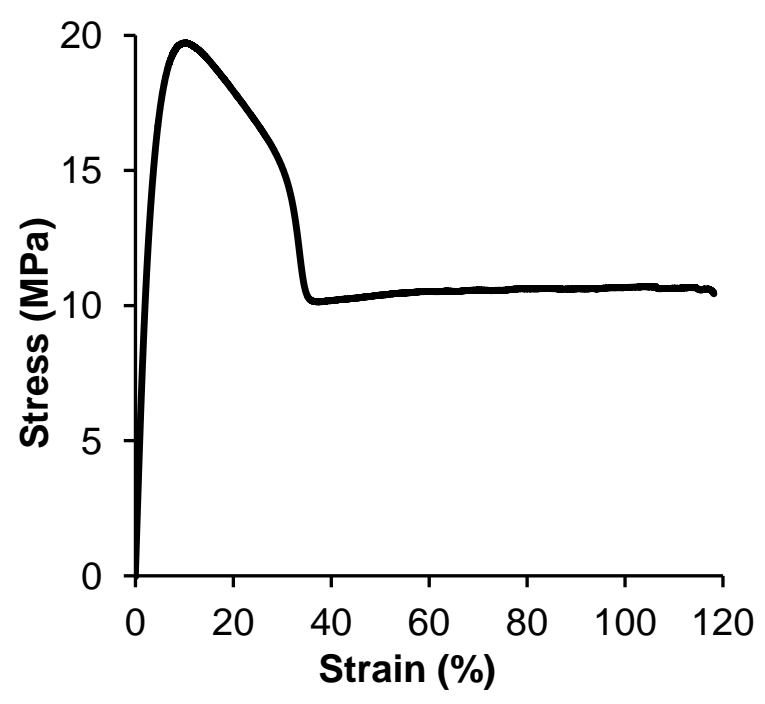

(a)

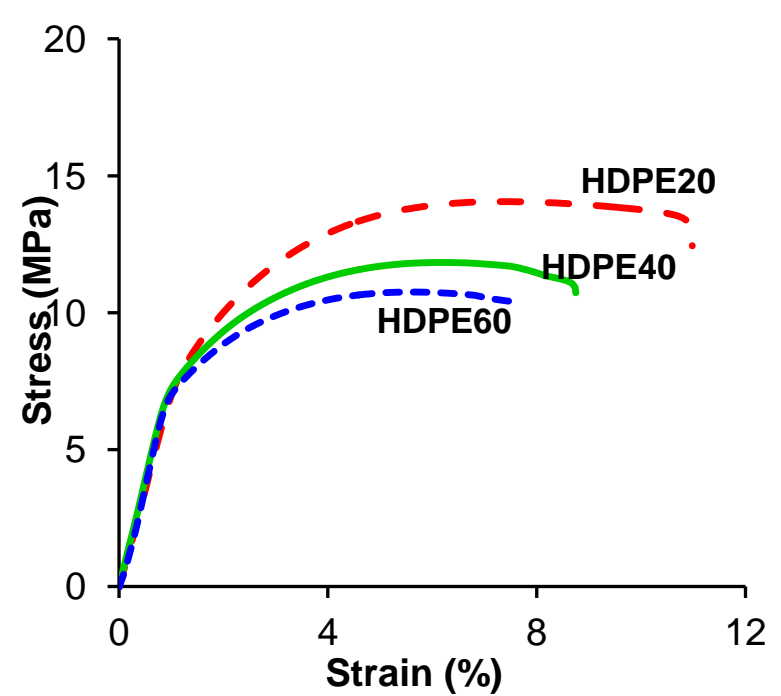

(b)

Figure 4. Tensile stress-strain curves for (a) neat HDPE and (b) syntactic foams having 20,40 and $60 \%$ cenospheres by weight.

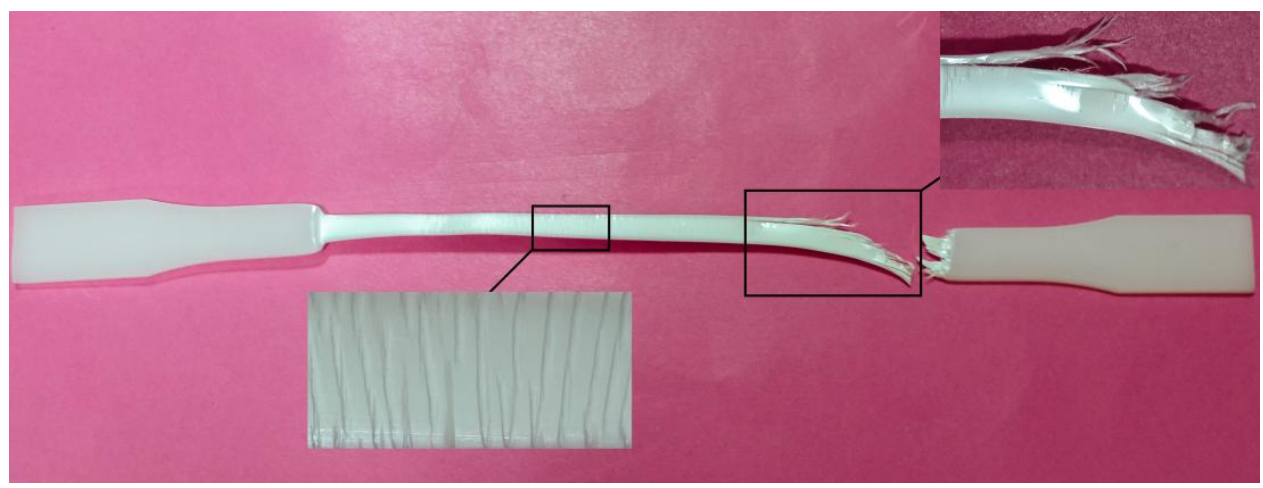

Figure 5. A representative failed specimen of HDPE. 


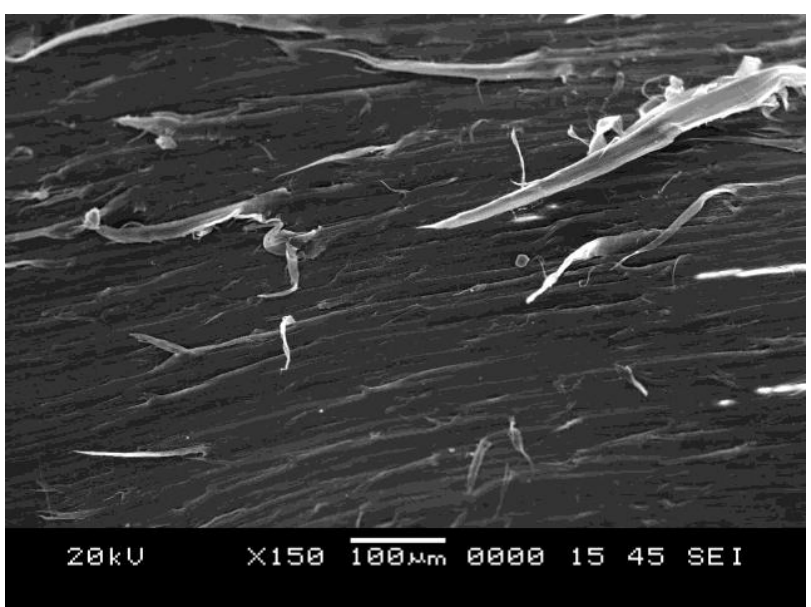

(a)

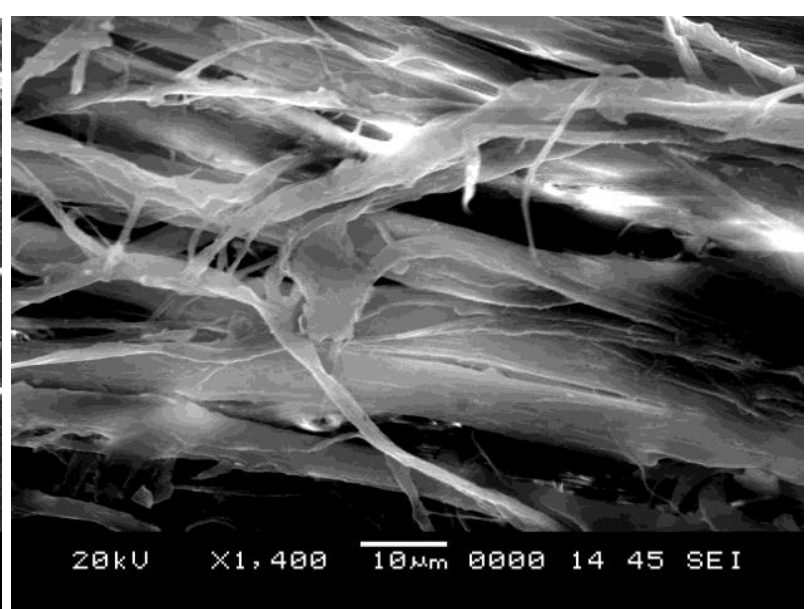

(b)

Figure 6. (a) Material flow lines with few separated fibers of HDPE before failure and (b) image close to the fracture zone showing formation of fibers that range from submicron to a few $\mu \mathrm{m}$ in diameter.

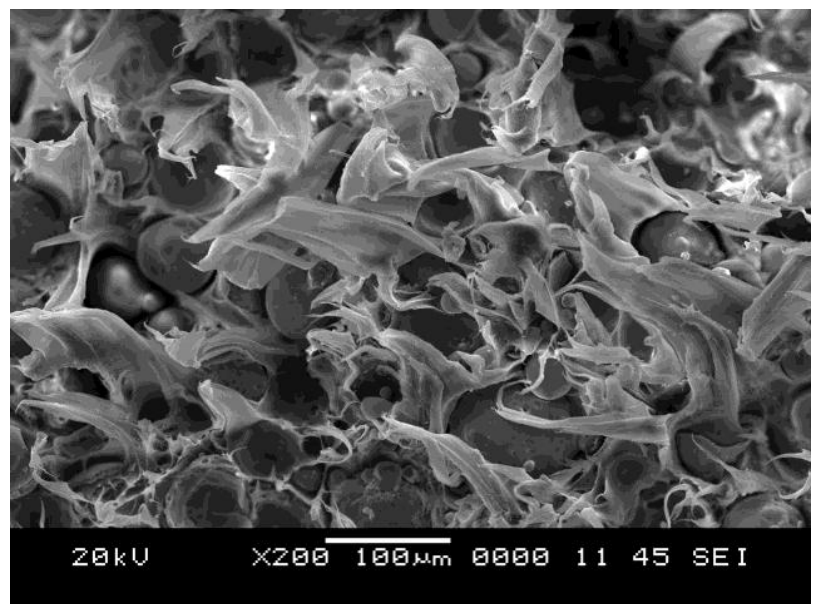

Figure 7. Failure surface of HDPE40 showing HDPE matrix deformation. 


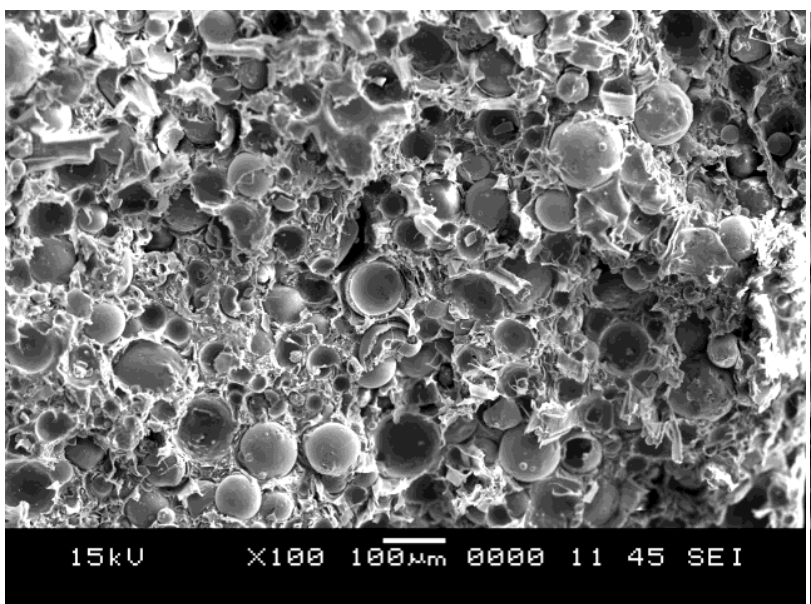

(a)

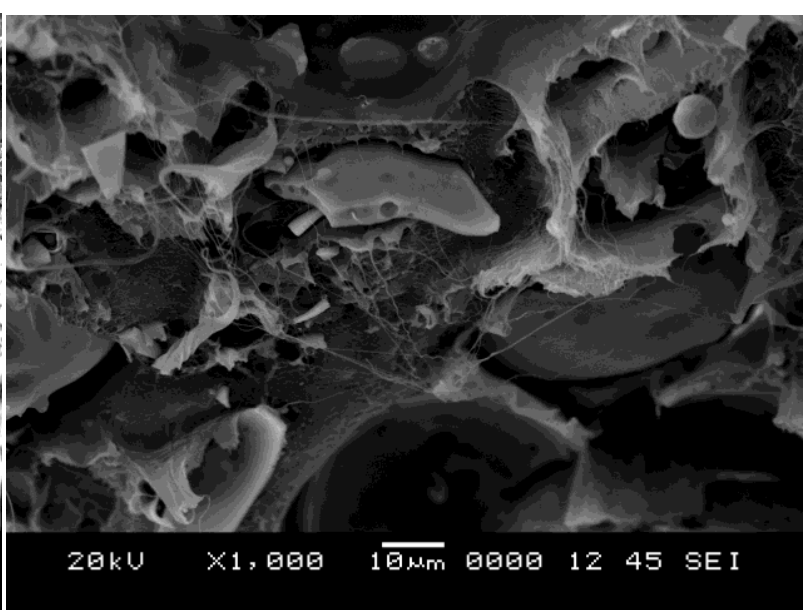

(b)

Figure 8. Fracture surface of HDPE60 specimen showing (a) plastic deformation of matrix and several intact cenospheres that have not fractured and (b) the higher magnification shows local plastic deformation of HDPE resulting in sub-micron scale diameter fibers of HDPE.

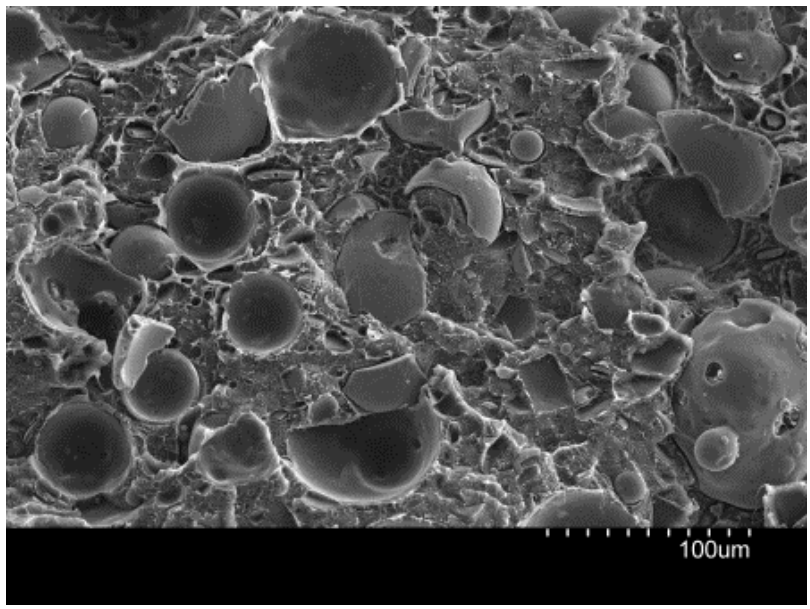

(a)

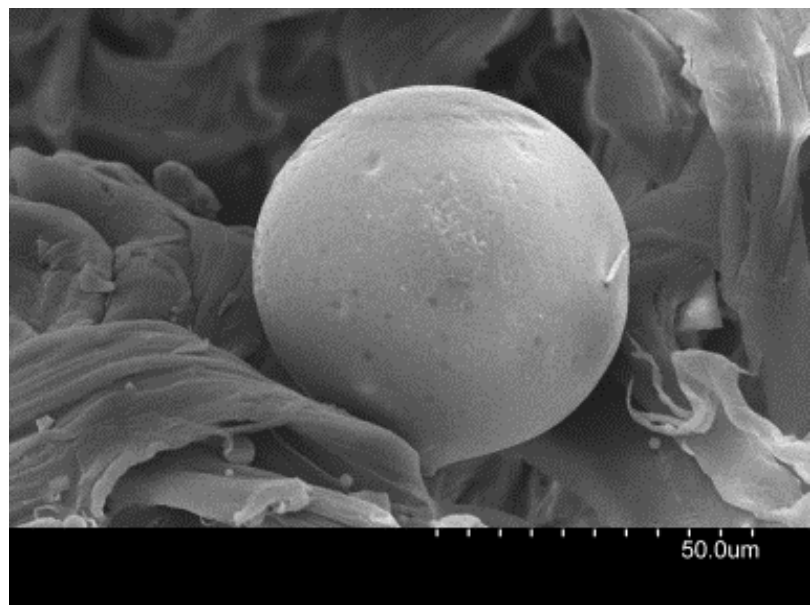

(b)

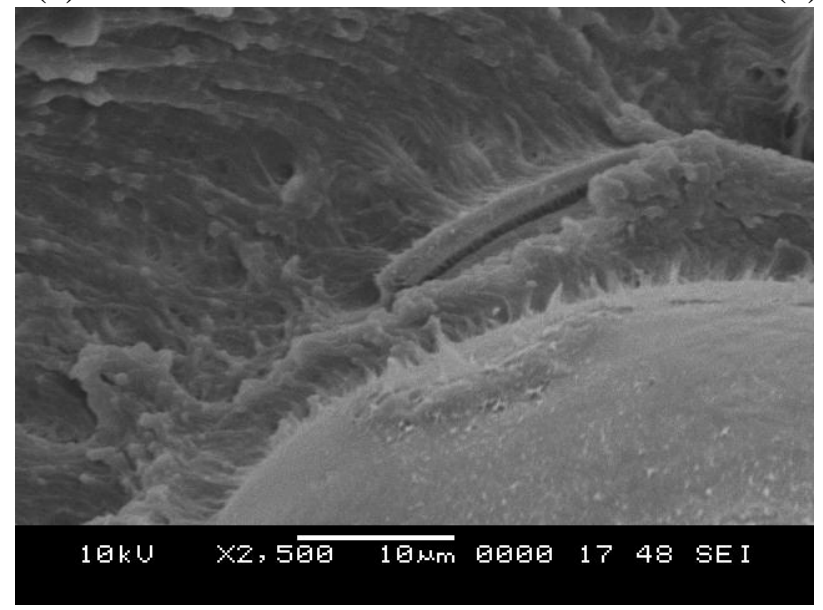

(c)

Figure 9. (a) Debris of cenospheres in a failed HDPE60 specimen. (b) A cenosphere in a HDPE60 syntactic foam specimen (c) interface between the treated constituents at higher magnification. 


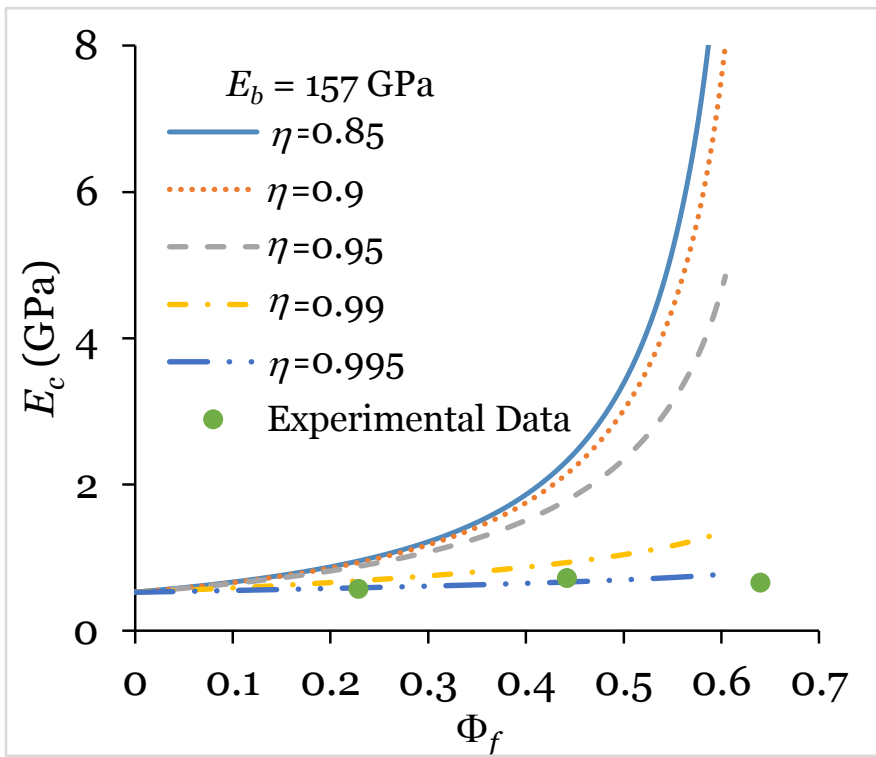

(a)

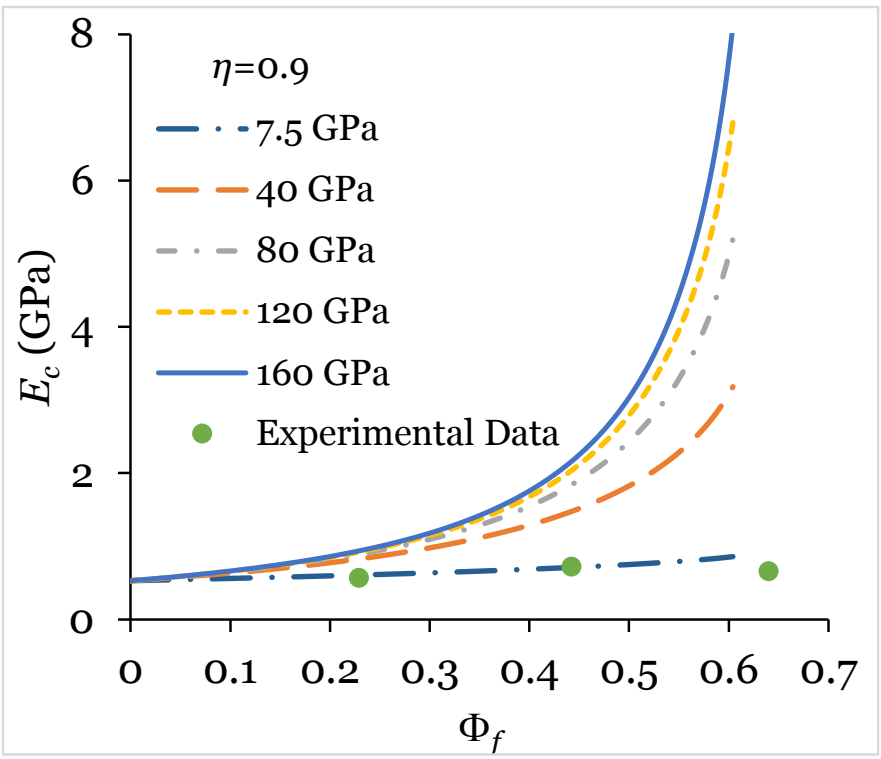

(b)

Figure 10. Results from Porfiri-Gupta model. In (a) the particle wall modulus obtained from the rule of mixtures method is kept constant and the radius ratio is varied. In (b) the radius ratio determined by density measurements is maintained constant and the ceramic modulus is varied. 


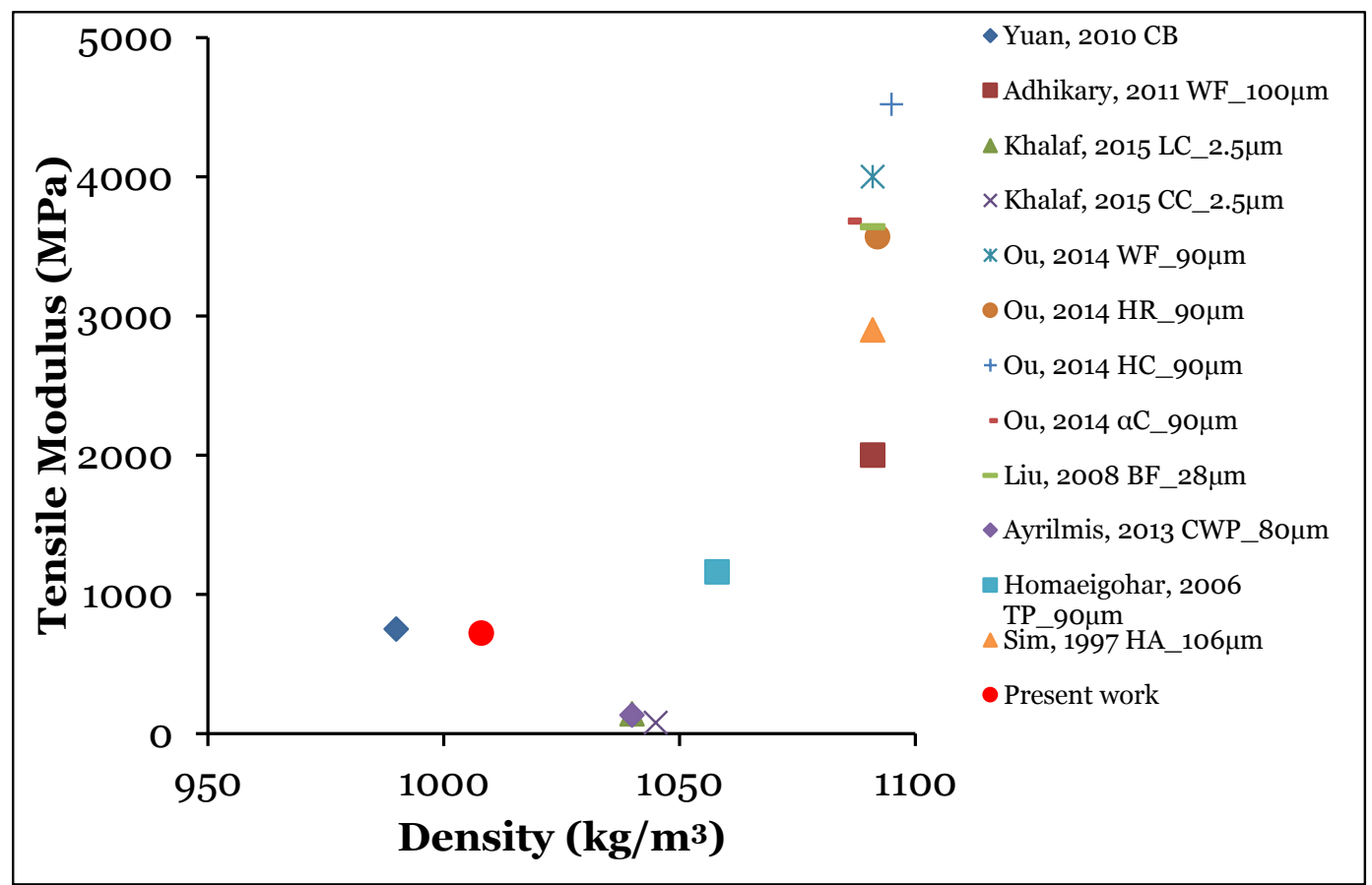

(a)

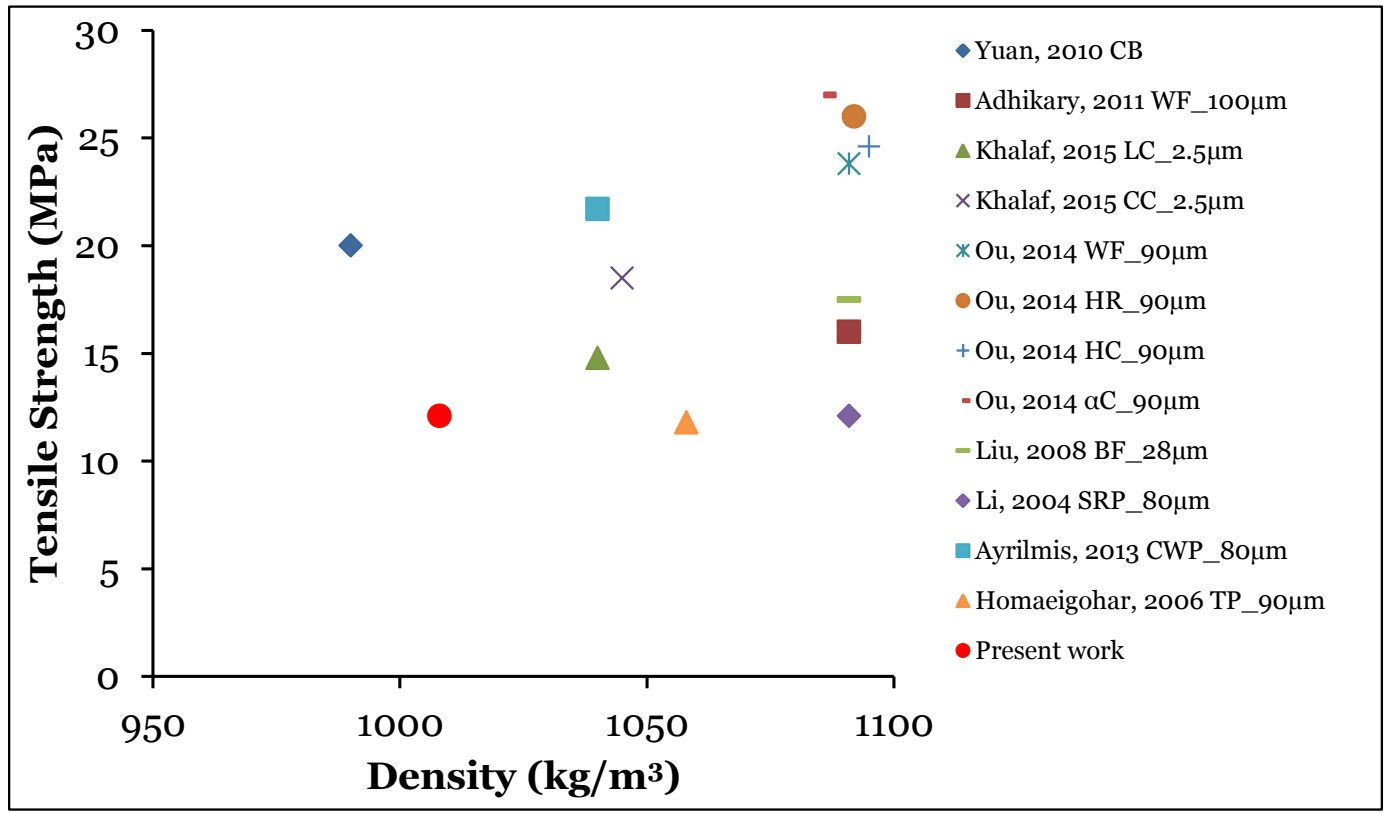

(b)

Figure 11. (a) Tensile modulus and (b) strength of HDPE composites plotted against density [31-39]. Some data points are extracted from figures with the best possible accuracy. 


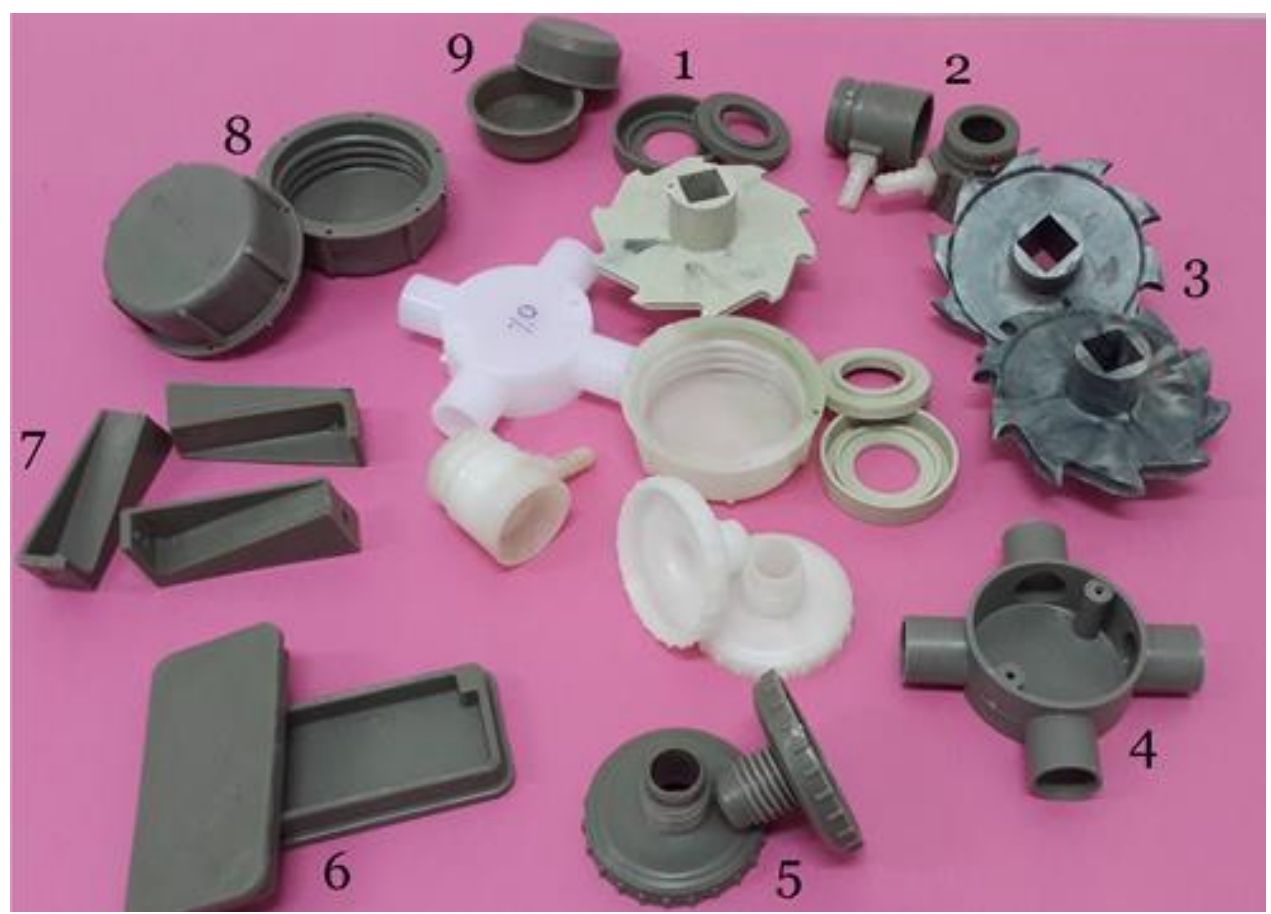

Figure 12. Eco-friendly components cast using injection molding technique 1 . bearing cover, 2 . automobile component used in liquified petroleum gas cylinder for gas mixtures, 3 . gear, 4 . electrical connector, 5 . water filter cap, 6. end cap for closure, 7. square base attachment for pipes, 8. Jerry can cap, and 9. bottle cap. Several original components made of pure HDPE are also displayed in the center. 

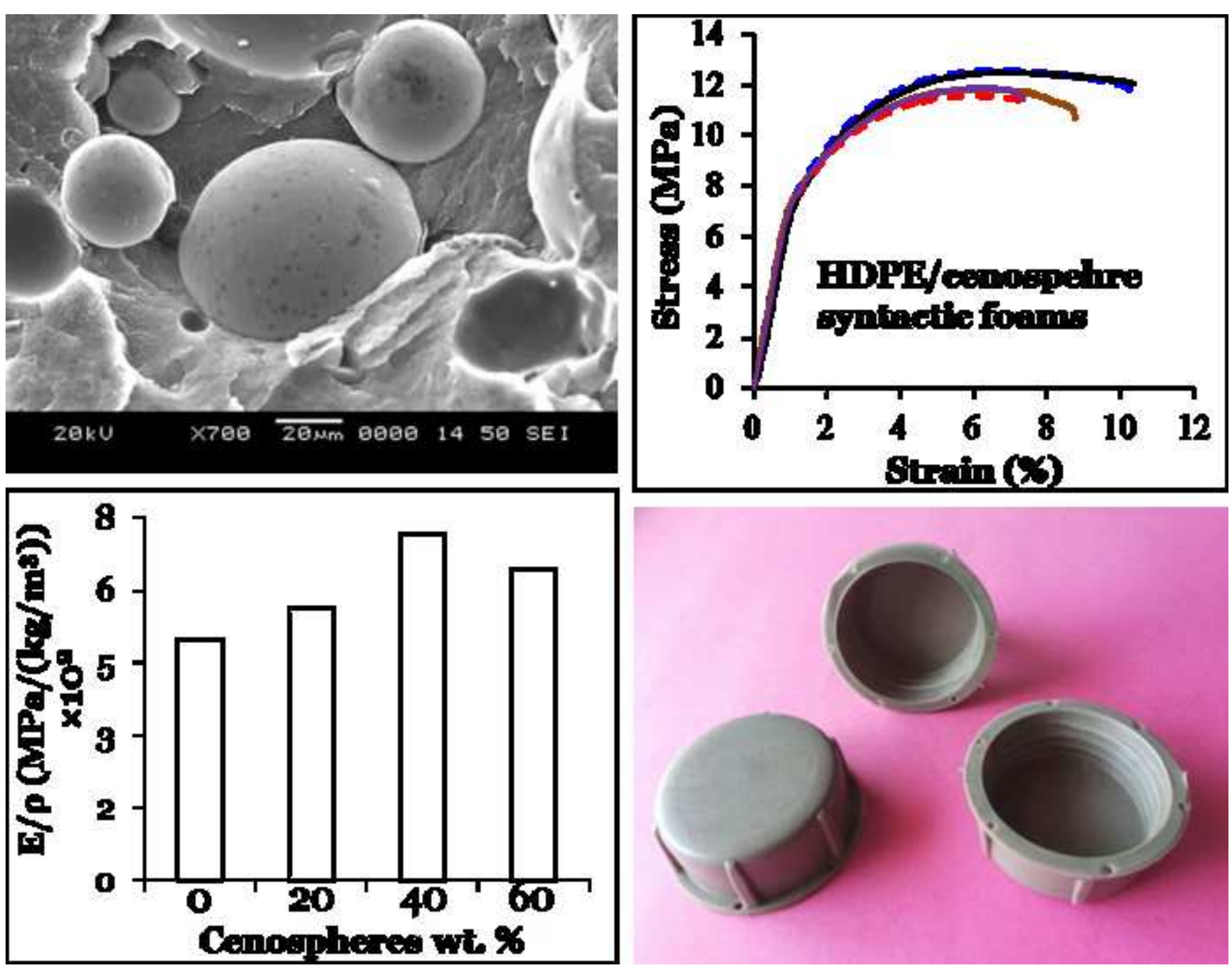